\title{
Numerical simulation of the impact of Anatolian and Caucasus Mountains on the precipitation distribution over the Black Sea
}

\author{
P. Ghafarian ${ }^{1}$, M. Azadi ${ }^{2}$, A. H. Meshkatee ${ }^{1}$, and M. M. Farahani ${ }^{3}$ \\ ${ }^{1}$ Department of Meteorology, Science and Research Branch, Islamic Azad University, Tehran, Iran \\ ${ }^{2}$ Atmospheric Sciences and Meteorological Research Center (ASMERC), Tehran, Iran \\ ${ }^{3}$ Institute of Geophysics, University of Tehran, Iran \\ Correspondence to: P. Ghafarian (p_ghaffarian@ hotmail.com)
}

Received: 5 October 2010 - Revised: 18 January 2012 - Accepted: 7 February 2012 - Published: 13 March 2012

\begin{abstract}
An attempt is made to examine the role of Anatolian and Caucasus mountain ranges in the precipitation distribution over the Black Sea region and to clarify the dynamical and physical mechanisms responsible for precipitation distribution over the region. Existence of a complex topography in the southern and eastern part of the Black Sea region makes it an important region for cyclogenesis. In this study the effect of Anatolian and Caucasus Mountains on the precipitating synoptic systems forming over the Black Sea are investigated. To this end, the Weather Research and Forecasting (WRF) model at $15-\mathrm{km}$ horizontal grid spacing has been used to evaluate the lifetime of a low pressure system that was accompanied with heavy precipitation on 14 March 2009 over the coastal region of the Black Sea. Two experiments were conducted. In the control experiment (CTL), the topographical features of the region were retained. In the sensitivity experiment (EXP), the Anatolian and Caucasus mountain ranges were removed. It is found that in the EXP, some fields including vertical motion, relative vorticity, humidity, geopotential height in low level, cloud water content and precipitation distribution in the region undergo significant changes. As such, in the EXP, the vorticity, and the cut-off low system over the Black Sea intensified. It is also seen that, under favorable conditions for precipitation occurrence, the precipitation intensity in the south and east coasts of the Black Sea decreased and the region of maximum precipitation shifted toward the "Sea of Azov" region, in the direction of the surface southerly winds.
\end{abstract}

\section{Introduction}

High and wide mountain ranges act as a barrier against the atmospheric flows and make changes in the path of the flows at the other side of the mountains. Local effects of the mountains on atmospheric flows may create different climatic regions at the other side of the mountain ranges. For example, application of climate models show that without Tibet, Central Asian climate is relatively humid and from when Tibet was added, this area has become drier (Manabe and Broccoli, 1990).

It is known that, while ascending a mountain barrier, moist flow normally will enhance the precipitation over the windward slope and crest. Both modeling (Alpert and Shafir 1989, 1991; Sinclair, 1994, among others) and observational (Rhea, 1978; Pandey et al., 1999; Neiman et al., 2002, among others) studies have shown that the amount of precipitation depends on the intensity of the upslope flow. For example, Neiman et al. (2002) showed that the orographic precipitation over the coastal range of central California is correlated best to the altitude of the low-level jet and crest of the topography at around $900 \mathrm{hPa}$. Using a slab model, Alpert (1986) could predict the precipitation profiles across the Sierras, Himalayas, and Equadorian Andes. He concluded that slopeinduced vertical velocities and decreased moisture availability with height are the main factors that mainly determine the precipitation distribution overhigh mountains.

Using the MM5 model, Cole (2004) investigated the relationship between orographic precipitation and the height and width of a barrier. He showed that maximum precipitation is highly dependent on the slope and width of the mountain as well as the horizontal wind velocity. The maximum 


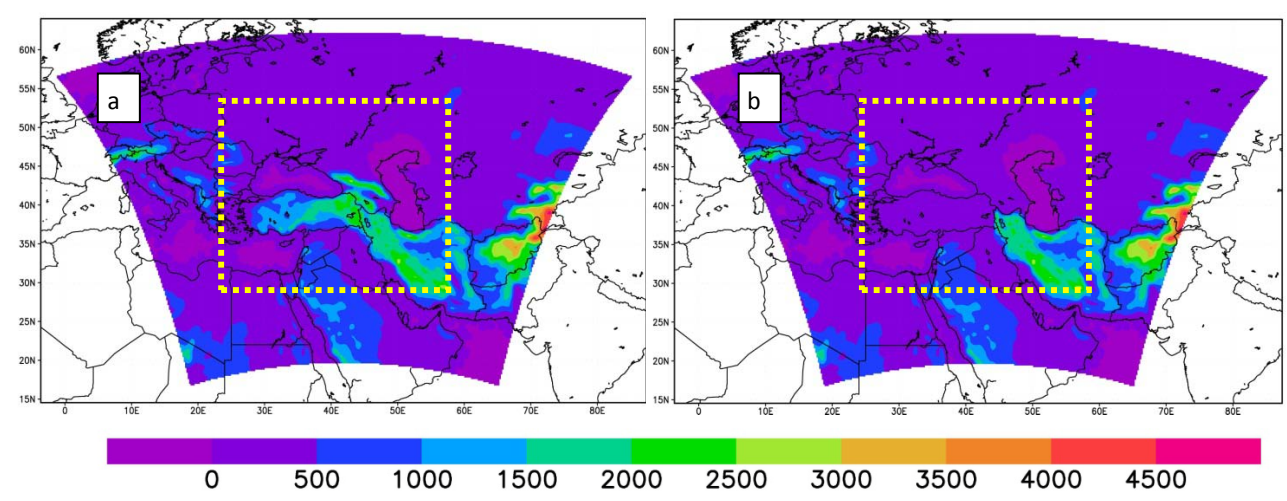

Fig. 1. Model topography for the inner domain in (a) CTL and (b) EXP.

precipitation is a strong function of barrier slope for relatively weak upstream flow, such that a low $(1000 \mathrm{~m})$ and narrow (25-km half-width) barrier has a greater surface precipitation maximum than a high $(2000 \mathrm{~m})$ and wide $(50-\mathrm{km}$ halfwidth) mountain of equivalent slope.

Moradi et al. (2008) examined the impact of the Zagross mountain ranges in Iran on the distribution of precipitation over the Iran region. They showed that without the Zagross mountain ranges, under favorable conditions for precipitation to occur, more precipitation would take place over the central desert of Iran located in the leeward side of the Zagross.

The aim of this article is to examine the role of Anatolian and Caucasus mountain ranges in the precipitation distribution over the Black Sea region and to clarify the dynamical and physical mechanisms responsible for precipitation distribution over the region.

Due to its peculiar morphology, physiographic characteristics and geographical location, the Mediterranean basin is an area prone to high-impact weather events, such as heavy precipitation or intense cyclogenesis (Davolio et al., 2009). Hence, to examine the effect of topography on precipitation distribution in the Black Sea region, a synoptic case was selected that caused heavy precipitation on 14 March 2009 over the coasts of the Black Sea.

The outline of this paper is as follows: The model setup is described in Sect. 2, and an overview of the synoptic situation is provided in Sect. 3. The results are summarized in Sects. 4 and 5.

\section{Model setup}

The Weather Research and Forecasting (WRF: Skamarock et al., 2001, 2008) model at 15-km horizontal grid spacing have been used. The model was run with two nested domains, with the larger domain covering the area that extends from $14^{\circ}$ to $64^{\circ}$ north and from $0^{\circ}$ to $90^{\circ}$ east and the smaller domain covers the Black Sea region from $25^{\circ}$ to $50^{\circ}$ north and from $20^{\circ}$ to $60^{\circ}$ east. The model has 27 sigma levels in the vertical with the top of the model set at a pressure of $50 \mathrm{hPa}$. The spatial resolutions are 45 - and $15-\mathrm{km}$ for the coarser and finer domains, respectively. Global terrestrial data including topography and land-use data with $2 \mathrm{~min}(\sim 4 \mathrm{~km})$ horizontal resolution were used to determine the topography and land-use on the model grid points. The initial and boundary conditions come from the operational $12 \mathrm{Z}$ runs of global forecasting system (GFS) of NCEP (National Center for Environmental Prediction) with one degree horizontal resolution. The selected options for the model physics are given in Table 1.

Two experiments were conducted. In the control experiment (CTL), the topographical features of the region were retained. In the sensitivity experiment (EXP), the Anatolian and Caucasus mountain ranges were removed. Figure 1 shows the model topography for the outer domain in the CTL and EXP. Also shown is the geographical location of the inner domain.

\section{Synoptic situation}

The topography around the Black Sea is highly variable. As shown in Fig. 1a, vast flat plain and low lands, with altitudes rarely exceeding $200-300 \mathrm{~m}$ above the sea level, are extended in the northern part. The Anatolian high plateau with its mountain elevations between 1000 to $5000 \mathrm{~m}$ is located in the south. In the east of the Black Sea, the Caucasus Mountains are located along the northwest - southeast direction. These high mountains include the Greater Caucasus mountain range in the northern part and the Lesser Caucasus Mountains in the southern part, with elevations having more than $2500 \mathrm{~m}$ at both ends and many peaks and heights with elevations of $4000 \mathrm{~m}$ or more.

In order to study the effect of Anatolian and Caucasus Mountains on precipitation distribution, a heavy precipitating synoptic system was selected that caused significant 

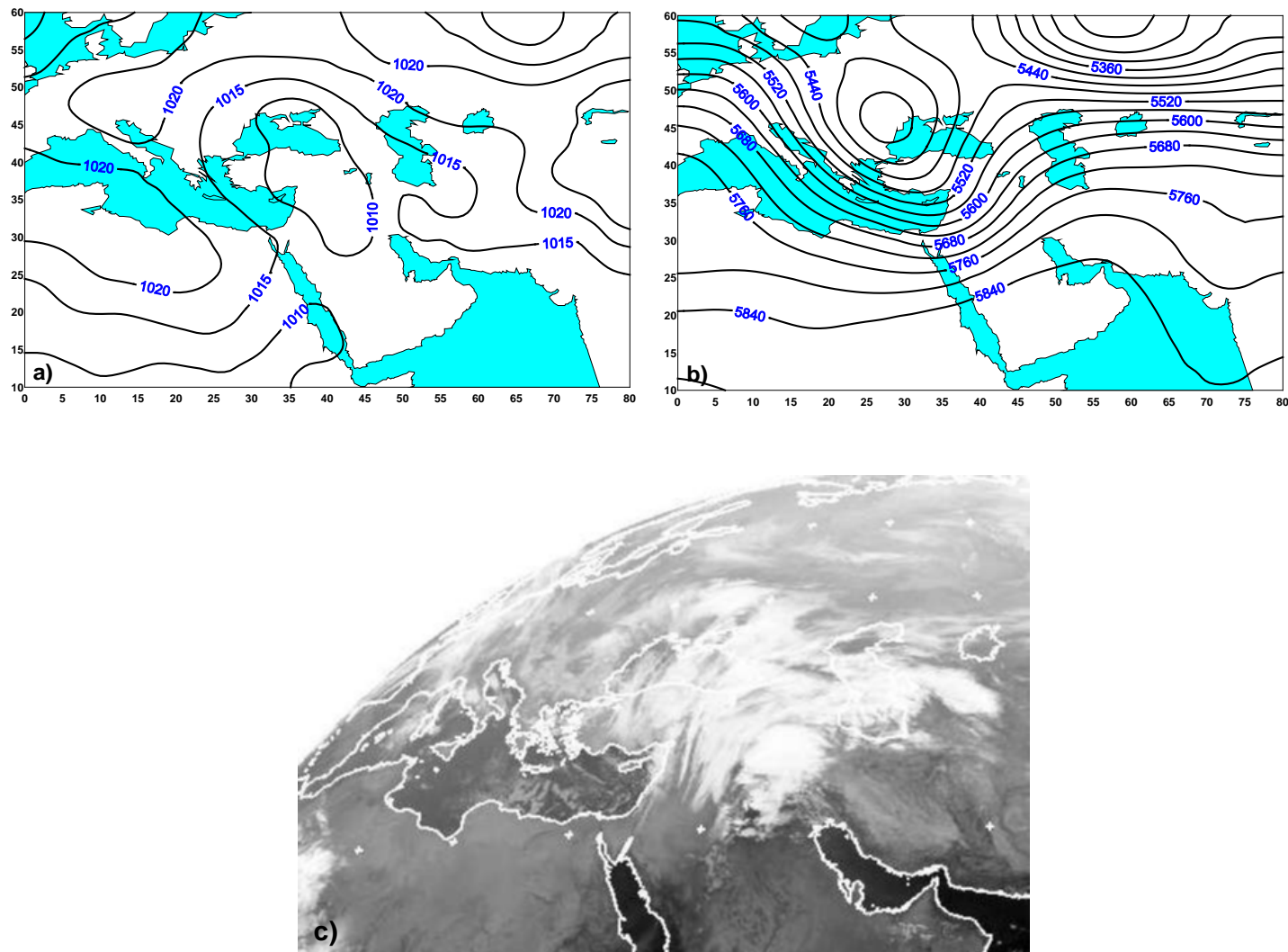

Fig. 2. (a) Analysis of sea level pressure (hPa) with $5 \mathrm{hPa}$ contour interval, (b) Analysis of $500 \mathrm{hPa}$ geopotential height (gpm) with $40 \mathrm{gpm}$ contour interval (from NCEP_NCAR Archive) and (c) Infrared satellite picture of Meteosat-7 valid at 00:00 UTC 14 March 2009.

Table 1. Settings for the model physics used in this study.

\begin{tabular}{llllllll}
\hline $\begin{array}{l}\text { WRF } \\
\text { Model configuration }\end{array}$ & Cumulus & $\begin{array}{l}\text { Planetary } \\
\text { Boundray layer }\end{array}$ & $\begin{array}{l}\text { Microphysic } \\
\text { radiation }\end{array}$ & $\begin{array}{l}\text { Long } \\
\text { radiation }\end{array}$ & $\begin{array}{l}\text { Short } \\
\text { wave }\end{array}$ & $\begin{array}{l}\text { Surface } \\
\text { wave }\end{array}$ & $\begin{array}{l}\text { Land surface } \\
\text { layer }\end{array}$ \\
\hline KFMYJ & Kain_Fritcsh & Mellor-Yamada-Janjic & Lin & RRTM & Goddard & M-O-Janic & NOAH \\
\hline
\end{tabular}

amount of precipitation on 14 March 2009 in the northern, southern and eastern coasts of the Black Sea, covering parts of Ukraine, Russia, Armenia, Georgia, Azerbaijan, Turkey and Iran. Examining the synoptic weather charts for 14 March 2009 shows that a surface low pressure with $1010 \mathrm{hPa}$ central pressure and northwest - southeast orientation is extended from the north of the Black Sea to Saudi Arabia (Fig. 2a). At $500 \mathrm{hPa}$ level a cut-off low is formed at the northwest of the Black Sea and is associated with a strong trough with an axis of negative tilt, which makes a southerly upslope flow over the Anatolian mountain ranges (Fig. 2b). The upper trough at $500 \mathrm{hPa}$ has not directly produced the southerly flows towards Anatolia, but has intensified the surface cyclone and thus the southerly flows have been initiated/intensified.
Figure 2c presents a satellite picture of Meteosat-7, showing the extended cloud coverage over the Black Sea at 00:00 UTC of 14 March 2009. Thick and high altitudes clouds can be clearly seen over the east and southeast of the Black Sea.

\section{Results and discussion}

The Weather Research and Forecasting (WRF) model, with the setup mentioned in Sect. 2, was used to simulate the lifetime of a low pressure system, from 12 March to 15 March 2009, which was accompanied with heavy precipitation from 12 to 14 March 2009 over the coastal region of the Black Sea. 


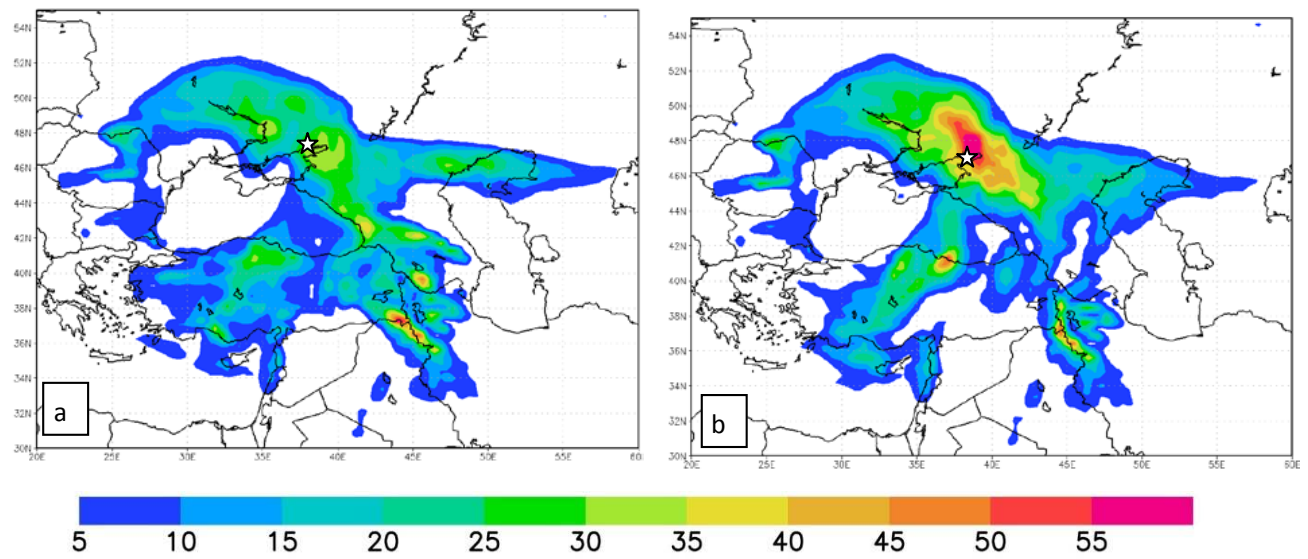

Fig. 3. 24-h forecasts of precipitation (mm) on 14 March 2009 for (a) CTL and (b) EXP.
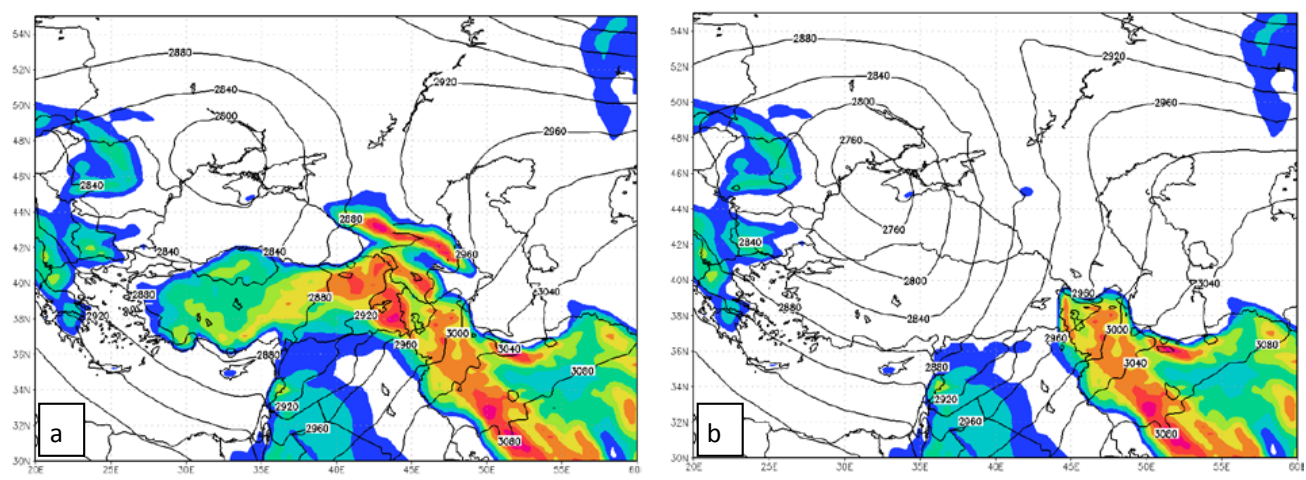

Fig. 4. Forecasts of $700 \mathrm{hPa}$ geopotential height (gpm) for 14 March 2009 at 00:00 UTC for (a) CTL and (b) EXP.

To verify the model results in the CTL, we used the observed accumulated precipitation on 14 March 2009 at several synoptic meteorological stations located in the northwest and west of Iran. The model outputs and corresponding observations for 24-hr accumulated precipitation are presented in Table 2.

As is seen from Table 2, the model is successful in predicting the yes/no rain event and in general there is good agreement between the model outputs and observed values of precipitation.

Figure $3 \mathrm{a}$ and $\mathrm{b}$ shows the 24-hr precipitation forecast for the inner domain ending on 14 March 2009 for the CTL and EXP. As seen from the Fig. 3a, the results of the CTL shows extensive amount of precipitation on the southern, southeastern and northern coast of the Black Sea, with a maximum over southern part of Turkey and Iran. Results of the EXP (Fig. 3b) show a decrease in precipitation amount in the southeastern and eastern and an increase in northern and southwestern coasts of the Black Sea, with its maximum now found over Ukraine, north of the Sea of Azov. For example, the 24-h precipitation forecasts at the point located at $47^{\circ} \mathrm{N}$ and $38^{\circ} \mathrm{E}$ point at the north of the Black Sea, indicated by a star in the figure, are 30 and $55 \mathrm{~mm}$ for the CTL and EXP, respectively.

The enhanced precipitation in the southern part of Anatolian mountains (Fig. 3) is due to the increased vertical motion and convergence of moist air currents. For the same reason a maximum of precipitation is seen in the windward side of the Caucasus Mountains. On the contrary, descending motions with reduced humidity over the northern part of mountains cause less amount of precipitation. After removing the mountains (EXP) the precipitation maxima is shifted to the region of "the Sea of Azov" (Fig. 3b).

To examine the change in the distribution of precipitation, some important fields including $700 \mathrm{hPa}$ geopotential height, relative vorticity, relative humidity and vertical motion are presented and analyzed.

The $700 \mathrm{hPa}$ geopotential height forecasts for 00:00 UTC 14 March 2009 for both CTL and EXP are shown in Fig. 4. In the CTL a cut-off low with a closed contour of $2800 \mathrm{~m}$ and its associated trough is seen over the north of the Black Sea that is extended over the Red Sea. In the EXP the cut-off low is deepened and its central height is reduced by $40 \mathrm{~m}$. 
Table 2. Accumulate precipitation on 14 March 2009 for observation and model output.

\begin{tabular}{llccccc}
\hline No & Station & Longitude $(\mathrm{N})$ & Latitude (E) & WMO no. & Observed precipitation & Model output precipitation \\
\hline 1 & Oroomieh & $37^{\circ} 32$ & $45^{\circ} 5$ & 40712 & 30.6 & 25.2 \\
2 & Tabriz & $38^{\circ} 5$ & $46^{\circ} 17$ & 40848 & 9.7 & 10.8 \\
3 & Ardebil & $38^{\circ} 15$ & $48^{\circ} 17$ & 40708 & 0 & 0 \\
4 & Sanandaj & $35^{\circ} 20$ & $47^{\circ} 00$ & 40747 & 5 & 7.2 \\
5 & Tehran Mehrabad & $35^{\circ} 41$ & $51^{\circ} 19$ & 40754 & 0 & 0 \\
\hline
\end{tabular}
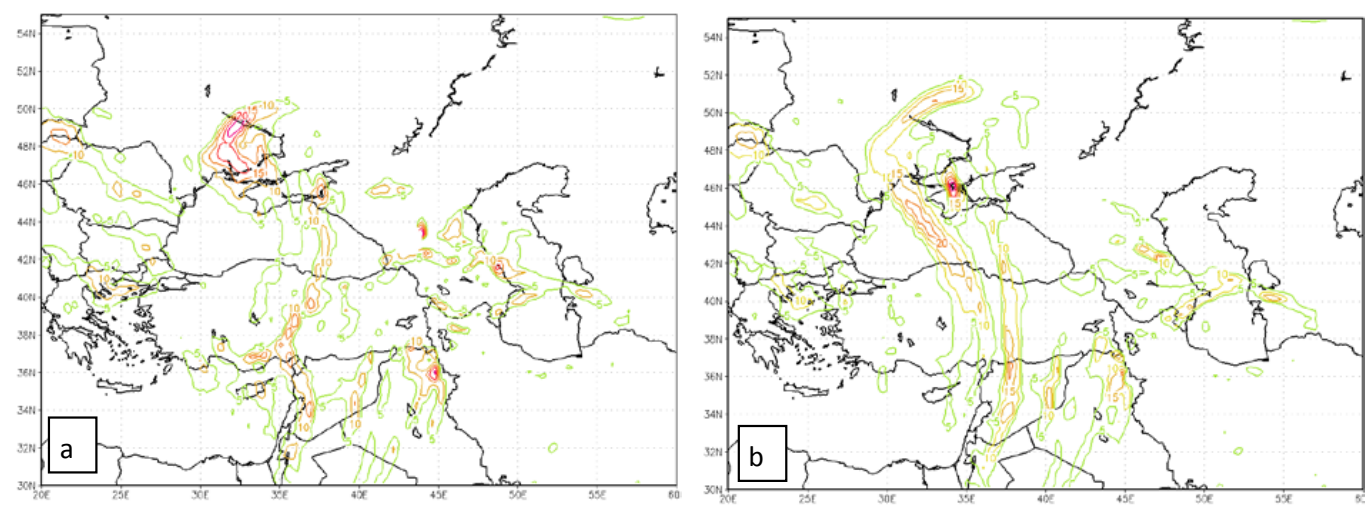

Fig. 5. Forecasts of $700 \mathrm{hPa}$ relative vorticity $\left(\mathrm{s}^{-1} \times 10^{5}\right)$ for 14 March 2009 at 00:00 UTC for (a) CTL and (b) EXP.

The $700 \mathrm{hPa}$ relative vorticity forecasts for 00:00 UTC 14 March 2009 for both CTL and EXP are shown in Fig. 5. The pattern of relative vorticity in the CTL run (Fig. 5a) shows a narrow band of low values with a minimum value of $10 \times 10^{-5}$ located over the central Anatolia and extended to southeast of the Mediterranean Sea. For EXP this band is more continuous and its maximum value of $15 \times 10^{-5}$ could be seen over Syria. Also, higher values of relative vorticity are now located over the west of the Sea of Azov, which might intensify the cut-off low over the region. This could be the reason for enhanced precipitation over the Sea of Azov in the EXP. Increase in the values of relative vorticity is clearly related to the elimination of the mountain ranges from the domain and thus increasing the depth of the atmospheric column.

Figure $6 \mathrm{a}$ and $\mathrm{b}$ shows relative humidity and vertical motion at $700 \mathrm{hPa}$ level. The overall pattern of the relative humidity is similar both in CTL and EXP. Though in the EXP, values of relative humidity and vertical motion ahead of the trough have increased, such that high values of relative humidity around $100 \%$ are now seen over the Sea of Azov and Ukraine. These increased values of relative humidity and vertical motion have a direct link with the intensification of the above mentioned cut-off low and hence vertical transport of moisture. For example, at the point located at $47^{\circ} \mathrm{N}$ and $38^{\circ} \mathrm{E}$ values of vertical motion in the CTL and EXP are 5 and $16 \mathrm{~cm} \mathrm{~s}^{-1}$. As is seen from the figure, after elimination of Anatolian mountain ranges from the domain, lifting vertical motion and hence vertical transport of moisture have been weakened.

Another quantity undergoing considerable changes is the cloud water content. To examine the changes in this quantity, a point with the maximum of precipitation in the EXP at $47^{\circ} \mathrm{N}$ and $38^{\circ} \mathrm{E}$ is selected. The vertical profile of cloud water content at this point for both the CTL and EXP with time is presented in Fig. 7. As seen from Fig. 7a, there is a maximum of $120 \times 10^{-6} \mathrm{~kg} \mathrm{~kg}^{-1}$ at $850 \mathrm{hPa}$ for $03: 00-$ 09:00 UTC on 14 March 2009, which has extended up to $550 \mathrm{hPa}$. In the EXP (Fig. 7b), on the other hand, the maximum is increased to $500 \times 10^{-6}$ and is seen at $900 \mathrm{hPa}$ on 06:00 UTC 14 March 2009. Unlike the CTL, high values of cloud water content (exceeding $100 \mathrm{~kg} \mathrm{~kg}^{-1}$ ) exist, starting from around 00:00 to 12:00 UTC on 14 March 2009. It is thus concluded that under favorable conditions for precipitation to occur, without Anatolian and Caucasus mountain ranges in the region, location of maximum precipitation is shifted towards the north of the Black Sea. 

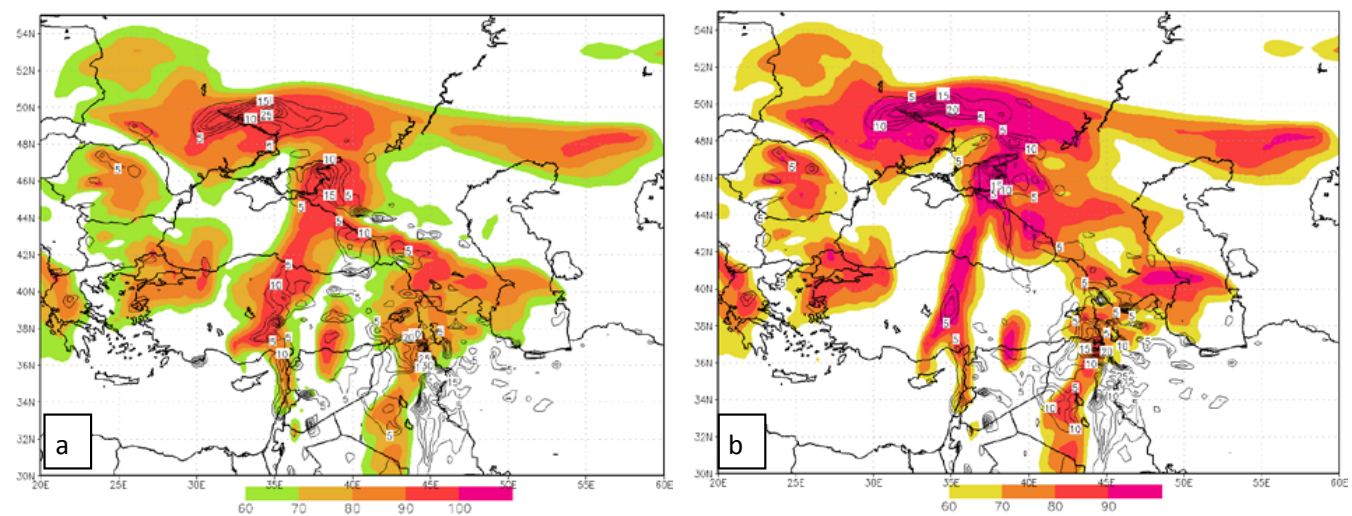

Fig. 6. Forecasts of $700 \mathrm{hPa}$ relative humidity (\%-shaded) and vertical Velocity ( $\mathrm{cm} \mathrm{s}^{-1}$ contours) for 14 March 2009 at 00:00 UTC for (a) CTL and (b) EXP.
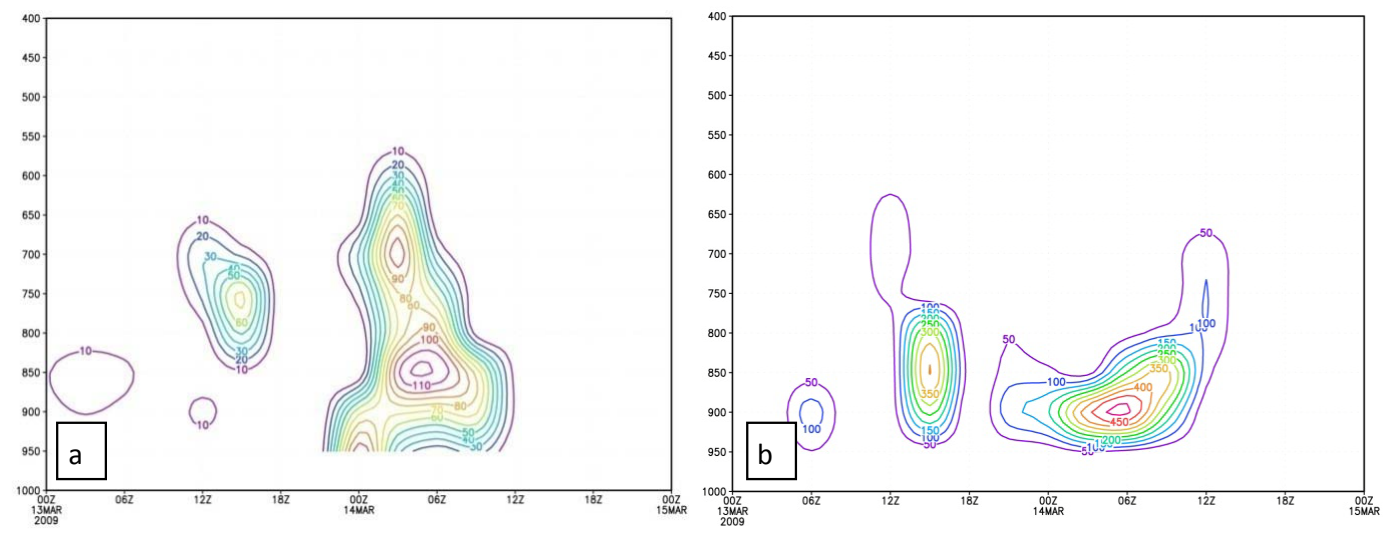

Fig. 7. Forecasts of the vertical profile of the cloud water content $\left(10^{-6} \mathrm{~kg} \mathrm{~kg}^{-1}\right)$, at $47^{\circ} \mathrm{N}$ and $38^{\circ} \mathrm{E}$ valid for 13 and $14 \mathrm{March} 2009$ for (a) CTL and (b) EXP. Contour interval is 10. The x-axis shows the time from 00:00 UTC 13 March to 00:00 UTC 15 March 2009. Vertical axis shows pressure levels from 1000 to $400 \mathrm{hPa}$.

\section{Conclusions}

The Weather Research and Forecasting (WRF) model was used to simulate the role of the Anatolian and Caucasus Mountains on the precipitation distribution over the Black Sea area. Due to the air-sea contrast and thus existing baroclinicity at lower levels, the eastern and western coasts of the Black Sea are prone to cyclogenesis (Trigo and Davies, 1999). A heavy precipitation synoptic system was simulated with and without the Anatolian and Caucasus Mountains. It is found that without Anatolian and Caucasus Mountains, the fields of vertical motion, relative vorticity, humidity, geopotential height in low level, cloud water content and precipitation distribution undergo significant changes. The precipitation maximum is located over Ukraine and the Sea of Azov. Since the Sea of Azov is located just at the north of the surface low pressure, the surface wind direction is thus in the windward side of the mountains. It is seen that in the
CTL, almost uniform precipitation occurred over the coasts of the Black Sea. While, without the mountains in the EXP, it is seen that because of the cut-off low intensification, its associated vertical motion ahead of the trough at $700 \mathrm{hPa}$ level have increased and thus an increase in precipitation over Ukraine could be seen in the direction of the southerly flow. Also, in the EXP, because of the increase in the depth of the atmospheric column, the extent and values of relative vorticity have increased that have lead to enhanced precipitation over the Sea of Azov. Finally we conclude that the Anatolian and Caucasus Mountains are not responsible for cyclogenesis and formation of the cut-off low at middle levels, but act to weaken the existing cut-off low. As such, the most important role of the mountains lies in their impact on the precipitation distribution and humidity over the Black Sea area. 
Acknowledgements. The authors would like to thank I. R. of Iran Meteorological Organization (IRIMO) and Atmospheric Science and Meteorological Research Center (ASMERC) for financial support.

They are also grateful to the editor and the anonymous reviewers for the precious remarks and comments that led to improving the initial version of this paper.

Edited by: N. R. Dalezios

Reviewed by: two anonymous referees

\section{References}

Alpert, P.: Mesoscale indexing of the distribution of orographic precipitation over high mountains, J. Appl. Meteor., 25, 532-545, 1986.

Alpert, P. and Shafir, H.: Mesog-scale distribution of orographic precipitation: Numerical study and comparison with precipitation derived from radar measurements, J. Appl. Meteor., 28, 1105-1117, 1989.

Alpert, P. and Shafir, H.: Role of detailed wind-topography interaction in orographic rainfall, Q. J. Roy. Meteor. Soc., 117, 421426, 1991.

Cole, B. A.: Sensitivity of orographic precipitation to changing ambient conditions and terrain geometries: An idealized modeling precipitation, J. Atmos. Sci., 61, 588-606, 2004.

Davolio, S., Miglietta, M. M., Moscatello, A., Pacifico, F., Buzzi, A., and Rotunno, R.: Numerical forecast and analysis of a tropical-like cyclone in the Ionian Sea, Nat. Hazards Earth Syst. Sci., 9, 551-562, doi:10.5194/nhess-9-551-2009, 2009.
Manabe, S. and Broccoli, A. J.: Mountains and Arid Climates of Middle Latitudes, Science., 247, 4939, 192-195, 1990.

Moradi, M., Meshkatee, A. M., Azadi, M., and Bidokhti, A. A.: Numerical simulation of the impact of orography on active synoptic weathersystems over Iran, J. Earth Space Phys., 34, 8, 25-44, 2008.

Neiman, P. J., Ralph, F. M., White, A. B., Kingsmill, D. E., and Persson, P. O. G.: The statistical relationship between upslopeflow and rainfall in California's coastal mountains: Observationsduring CALJET, Mon. Wea. Rev., 130, 1468-1492, 2002.

Pandey, G. R., Cayan, D. R., and Georgakakos, K. P.: Precipitation structure in the Sierra Nevada of California during winter, J. Geophys. Res., 104, 12019-12030, 1999.

Rhea, J. O.: Orographic precipitation modelfor hydrometeorologicaluse, Ph.D. dissertation, Colorado State University, Atmospheric Science Paper 287, 198 pp., 1978.

Sinclair, M. R.: A diagnostic model for estimating orographic precipitation, J. Appl. Meteor., 33, 1163-1175, 1994.

Skamarock, W. C., Klemp, J. B., and Dudhia, J.: Prototypes for the WRF (Weather Research and Forecast) model, Preprints, Ninth Conf. on Mesoscale Processes, Fort Lauderdale, FL, Am. Meteor. Soc., CD-ROM, J1.5., 2001.

Skamarock, W. C., Klemp, J. B., Dudhia, J., Gill, D. O., Barker, D. M., Duda, M. G., Huang, X., Wang, W., and Powers, J. G.: A description of the Advanced Research WRF Version 3, NCAR Tech. Note NCAR/TN-475+STR, 2008.

Trigo, I. F. and Davies, T. D.: Objective Climatology of Cyclones in the Mediterranean Region, J. Climate, 12, 1685-1699, 1999. 